\title{
OPTIMAL PATH SELECTION FOR EMERGENCY RELIEF SUPPLIES AFTER MINE DISASTERS
}

\author{
Zeng, J., ${ }^{* * *}$; Yao, Q. G. ${ }^{*, * *, \#}$; Zhang, Y. S. ${ }^{* * *}$; Lu, J. T. ${ }^{* * * *, * * * * * \#}$ \& Wang, M. \\ *College of Economics and Management, Shandong University of Science and Technology, \\ Qingdao 266590, China \\ ** Shandong Vocational and Technical University of International Studies, Rizhao 276826, China \\ ${ }^{* * *}$ College of Mining and Safety Engineering, Shandong University of Science and Technology, \\ Qingdao 266590, China \\ ${ }^{* * * *}$ School of Economics and Management, Taiyuan University of Science and Technology, \\ Taiyuan 030024, China \\ ${ }^{* * * * *}$ Research Center for Corporate Social Responsibility, Taiyuan University of Science and \\ Technology, Taiyuan 030024, China \\ ******* Lahore Business School, University of Lahore, Lahore 54590, Pakistan \\ E-Mail: yqg@sdkd.net.cn, lut2002@163.com (" Corresponding authors)
}

\begin{abstract}
Due to the inappropriate path caused by traffic control, climatic conditions, and inconsistent regional economic development, etc., the transportation efficiency of emergency relief supplies is low in mining areas in China. To improve the transportation efficiency, a road impedance function model was proposed based on the uniqueness of emergency relief supplies' transportation after mine disasters. The model, which aimed to solve the optimal transport time conforming to practical traffic conditions, was designed in accordance with China's road design norms and actual traffic flows while considering random delays at road junctions. The weight of path was calculated from the road impedance function model and traffic allocation simulation data. The feasibility and universality of the model were proved by performing simulations under normal traffic, rainfall and traffic control conditions. Results indicate that the optimal path selection by the Dijkstra algorithm achieves a high accuracy. Time cost under rainfall and traffic control conditions increases by $3.3 \%$ and $1 \%$, respectively, compared with the normal condition. This study provides new ideas to select transport path for emergency relief supplies. (Received in April 2019, accepted in July 2019. This paper was with the authors 1 month for 1 revision.)
\end{abstract}

Key Words: Path Selection, Emergency Relief, Material Transport, Path-Weight

\section{INTRODUCTION}

With the continuous improvement of mining technologies in recent years, the overall incidence rate of accidents in large mines in China has decreased dramatically. However, some accidents like gas explosion [1], rock burst [2], roof collapse [3] and underground water inrush [4] occasionally occur due to non-artificial factors. Emergency relief supplies must be transported to mining areas in a timely and effective manner once a mine disaster occurs.

However, most mines have relatively inadequate supporting rescue conditions, facilities, and materials. After the occurrence of mine disasters, it is generally difficult to supply relief supplies immediately. Instead, relief supplies are dispatched from adjacent provinces, cities and districts. Due to great differences in road design norms and actual traffic flows, traffic conditions at road junctions in the same city may be inconsistent, which cause difficulties in trans-provincial, trans-city and trans-district dispatching of relief supplies, thereby influencing the timely delivery of emergency relief supplies. Therefore, choosing the optimal transport path to deliver emergency relief supplies to mines in the first time after accidents is of significance in terms of protecting the life security of mining workers. 


\section{STATE OF THE ART}

Thus far, only a few studies have directly investigated the optimal path selection of emergency rescue material transportation after a mine disaster. However, this problem is essentially the optimal path selection problem. Such a problem is usually solved by dynamic traffic assessment (DTA), signal setting, traffic flow prediction, etc. Xie and Wang [5] proposed a system that integrated traffic control and optimal path selection. They also developed a stop/go decision system to help improve the traffic efficiency. Based on the current road pricing methods, Groot et al. [6] presented three new schemes to obtain the optimal traffic distribution targeting the minimum time cost and traffic emissions. De Maio and Vitetta [7] explored and established the optimal path selection model in traffic networks from three levels. To prepare Tsunami disasters, Kim et al. [8] established an optimal path selection model for evacuation. In terms of DTA, Duell et al. [9] proposed a new modelling framework based on a current DTA strategy to find optimal paths in Sydney Central Business District network. Meneguzzer [10] presented the dynamic process (DP) models between signal control and path selection. Hanczar and Kaleta [11] identified and evaluated the potential savings between classical vehicle and inventory routing problems. Meng et al. [12] constructed a mesoscopic DTA simulation model and proposed a multi-modal DTA model considering private cars, subway, buses and bicycles. Meanwhile, Florian et al. [13] described a simulation-based DTA model using an online intelligent transportation system, and accurate results were obtained by this model with few computations.

As for traffic signal control and model prediction, many scholars performed related studies. For example, Marcianò et al. [14] described a traffic signal setting framework of road intersections, and carried out an experimental test to prove its effectiveness. They also proposed a traffic signal setting model for urban emergency evacuation [15]. Based on GA, Cantarella and Vitetta [16] analysed and optimized the urban network layout and link capacity. $\mathrm{Yu}$ et al. [17] proposed a framework for optimal traffic signal control in order to find the optimal signal settings and minimum time cost in a road network. Lee et al. [18] developed a group-based traffic control strategy, which optimized signal timings, and this strategy was proved to be effective by mathematical frameworks and computer simulations. Sirmatel and Geroliminis [19] presented economic model predictive control (MPC) schemes based on the macroscopic fundamental diagram; the proposed model improved mobility in large-scale urban road networks. Jamshidnejad et al. [20] proposed a sustainable MPC model in urban traffic networks, and a case study proved its effectiveness. Following this model, Lin et al. [21] used MPC to achieve control urban traffic networks.

Although this problem is essentially an optimal path selection problem, it presents some differences compared with conventional path selection problem. On the one hand, traffic and economic conditions in mining areas are usually worse than those in urban areas. Moreover, the emergency rescue materials in the mining areas are relatively lacking. On the other hand, road design criteria and actual road traffic flows in different regions are quite different. The situations at each intersection in the same area also vary, thus causing certain difficulties in the inter-provincial, inter-city, and inter-regional transportation of emergency rescue materials. Both factors can affect the timely transportation of emergency rescue materials. Therefore, considering the special traffic situations in mining areas, finding and solving the optimal path selection combined with the road impedance function model and the actual road conditions in mining areas is a very significant research topic.

The rest of this study is organized as follows. Section 3 introduces the optimal path selection model, path constraints, and model parameters. Section 4 simulates and compares the differences of the optimal path respectively under normal traffic condition, rainfall condition, and traffic control condition. Section 5 summarizes the conclusions. 


\section{METHODOLOGY}

In disaster-affected areas, material supply is characteristic of urgency. In other words, emergency relief supplies have to be delivered in the shortest time. The shortest transport time is determined by several factors, such as the length of transport path, traffic flow, delays at road junctions, and road design norms. The problem of selecting the optimal transport path for emergency relief supplies is equal to calculating the path with the minimum time cost $(T)$.

\subsection{Construction of the path selection model}

Transport time is the primary index of path selection. However, the classical Bureau of Public Roads (BPR) road impedance function calculates the transport time based on the designed vehicle speed, but neglects the transport characteristics of emergency relief supplies and the impacts of human, vehicle and road on traffic flow. The original impedance function is propagated and corrected in the present study. With comprehensive consideration to traffic flows and delays at road junctions, a road impedance function model that better conforms to the practical situation is constructed as follows in Eq. (1).

$$
f_{i}(t)=T_{i}+T_{C_{i}}
$$

where, $f_{i}(t)$ is the total time from starting point to terminal, $T_{i}$ is the transport time from the starting point to the terminal in the classical BPR model, and $T_{C_{i}}$ is the delay of vehicles at road junctions due to traffic lights.

Classical BPR model: In the Classical BPR model, $T_{i}$ is expressed as follows.

$$
T_{i}=\frac{t_{0}}{\alpha}\left[1+\left(\frac{V_{i}}{C_{i}}\right)^{\beta}\right]
$$

where, $t_{0}$ is the transport time of the path under no barriers (h), $V_{i}$ is traffic flow of the path $(\mathrm{pcu} / \mathrm{h}), C_{i}$ is the actual capacity of the path $(\mathrm{pcu} / \mathrm{h}), \alpha$ and $\beta$ are respectively the regression parameters and correction factors. In addition, $\alpha$ and $\beta$ are set the typical values of 0.15 and 4 .

In the present study, $\alpha$ and $\beta$ were reset based on the abundant practical traffic data in China. The values ranges of $\alpha$ and $\beta$ were 1-2 and 3.5-4.5 for a fast path, 2-3 and 3.5-4.5 for the arterial road, and 2.5-3.5 and 3.5-4.5 for the corresponding secondary arterial roads. The suggested values of $\alpha$ and $\beta$ are 2.5 and 4 , respectively.

Delay model at the road junction: In the delay model at the road junction, $T_{C_{i}}$ can be expressed in Eq. (3) as follows.

$$
T_{C_{i}}=\frac{T(1-\lambda)^{2}}{2\left(1-\lambda^{x}\right)}+\frac{x^{2}}{2 q(1-x)}-0.65\left(\frac{T}{q^{2}}\right)\left(\frac{T}{q^{2}}\right)^{\frac{1}{3}} x^{(2+5 x)}
$$

where, $T$ is periodic time of traffic lights, $\lambda$ is the proportion of traffic lights, $q$ is the actual traffic flow at road junction (pcu/h), and $x$ is the degree of saturation.

A quantitative model of traffic impedance is constructed based on the target principle of the shortest total transport time. This is known as the road impedance function, based on which different road sections in the path network are weighted. The optimal path from the starting point to the terminal is calculated by the Dijkstra algorithm.

Given a weighted directed map $(G)$ and source point $\left(v_{0}\right)$, the vertex in the network $N=(V, E)$ is divided into the following two sets:

(1) $S$ set: terminal of the shortest path (initially including $v_{0}$ ) is calculated.

(2) $V-S$ set: vertex of the shortest path is not calculated (initially $V-\left\{v_{0}\right\}$ ).

According to the increasing order of length of the shortest path from the vertices and $v_{0}$, the vertex elements in the $V-S$ set are added into the $S$ set one by one [22]. In one process, 
the length of path passing from $v_{0}$ to the vertices in $S$ set is smaller than or equal to the length of paths from $v_{0}$ to the vertices in the $V-S$ set.

A directed weighted adjacent matrix arcs is used to express the weighted directed network $G$. Here, $G . \operatorname{arcs}[i][j]$ reflects weights on the arc $\left\langle v_{i}, v_{j}\right\rangle$. When there is no $\left\langle v_{i}, v_{j}\right\rangle$, it is recorded as $\operatorname{Garcs}[i][j]=\infty$. To realize the Dijkstra algorithm, the following assisted data structures have to be involved:

(1) One-dimensional array $S[i]$ : determines whether the distance from $v_{0}$ to $v_{i}$ is the shortest path or not. If it is true, this path is the shortest one. If it is false, it is not determined.

(2) One-dimensional array Path[i]: the direct precursor vertex of $v_{i}$ is recorded from the shortest path from $v_{0}$ to $v_{i}$. Initial value: if there is an arc from $v_{0}$ to $v_{i}, \operatorname{Path}[i]$ is $v_{0}$, otherwise, it is -1 .

One-dimensional array $D[i]$ : the current shortest path from $v_{0}$ to $v_{i}$ is recorded. Initial value: if there is an arc from $v_{0}$ to $v_{i}, D[i]$ is the weight of this arc; otherwise, it is $\infty$.

\subsection{Numerical simulation case}

In accordance with the practical situations in a region, the main path networks in four regions are used as the research objects. They are illustrated into the traffic map in Fig. 1.

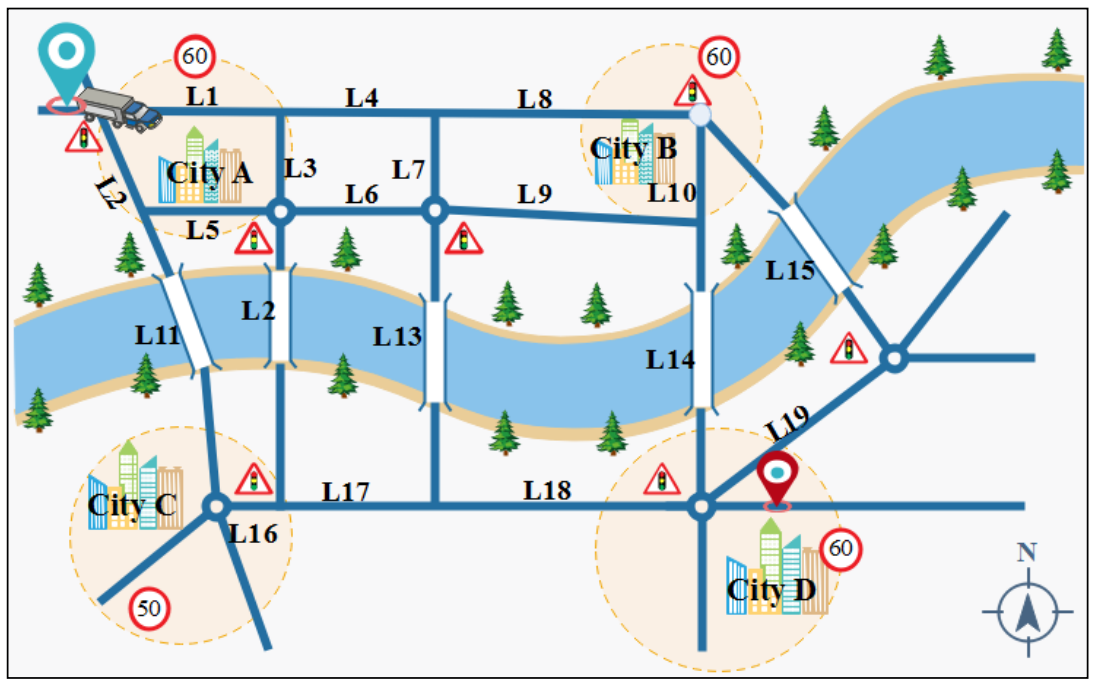

Figure 1: Path network topology.

As can be seen in Fig. 1, a mine disaster occurs in City D, and requires the supply of emergency relief materials from City A. Each section between these two cities might be used as the path. Road junctions are used as the nodes. Road sections are numbered L1-L19. Lengths of road sections are shown in Table I.

Table I: Lengths of road sections.

\begin{tabular}{|c|c|c|c|c|c|c|c|c|c|}
\hline $\begin{array}{c}\text { Road } \\
\text { section }\end{array}$ & $\begin{array}{c}\text { Length } \\
(\mathrm{km})\end{array}$ & $\begin{array}{c}\text { Road } \\
\text { section }\end{array}$ & $\begin{array}{c}\text { Length } \\
(\mathrm{km})\end{array}$ & $\begin{array}{c}\text { Road } \\
\text { section }\end{array}$ & $\begin{array}{c}\text { Length } \\
(\mathrm{km})\end{array}$ & $\begin{array}{c}\text { Road } \\
\text { section }\end{array}$ & $\begin{array}{c}\text { Length } \\
(\mathrm{km})\end{array}$ & $\begin{array}{c}\text { Road } \\
\text { section }\end{array}$ & $\begin{array}{c}\text { Length } \\
(\mathrm{km})\end{array}$ \\
\hline L1 & 24.3 & L5 & 15.5 & L9 & 31.2 & L13 & 42.7 & L17 & 16.1 \\
\hline L2 & 19.2 & L6 & 15.8 & L10 & 18.3 & L14 & 42.7 & L18 & 34 \\
\hline L3 & 18 & L7 & 18.4 & L11 & 44 & L15 & 52.1 & L19 & 46.3 \\
\hline L4 & 15.8 & L8 & 33 & L12 & 43.4 & L16 & 13.4 & - & - \\
\hline
\end{tabular}

Combined with the above practical traffic flows, practical accessible nodes and sections are selected. The original road network is abstracted as a topological map (Fig. 2) for operation. 


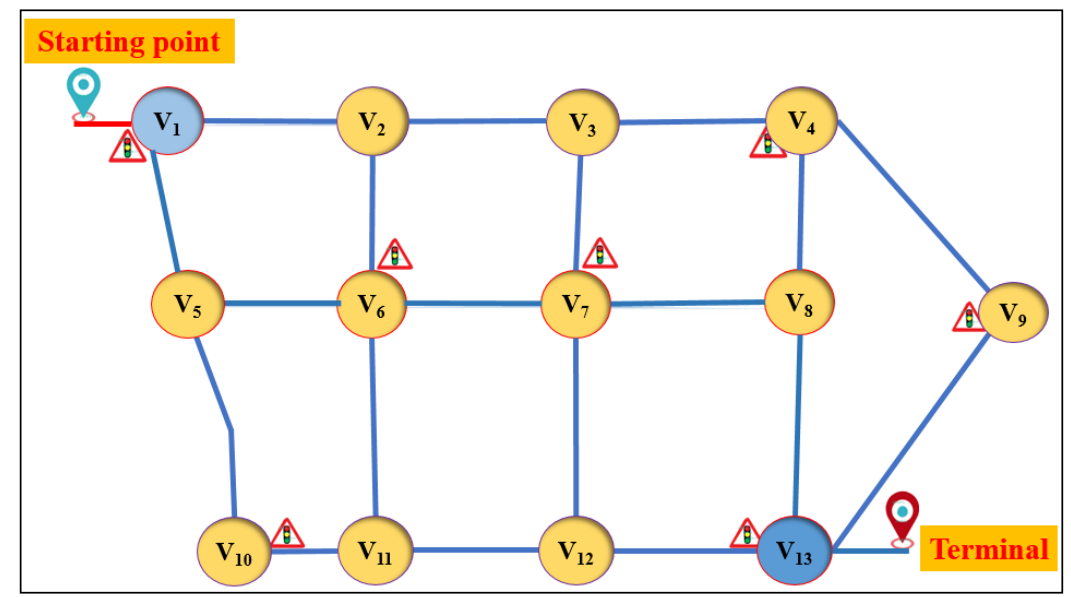

Figure 2: The simplified topological map of the path network.

\section{RESULT ANALYSIS AND DISCUSSION}

The design speeds of roads are related to the type and city conditions. Urban roads can be divided into four types according to the urban road design norms. Design speeds are $45 \mathrm{~km} / \mathrm{h}$, $55 \mathrm{~km} / \mathrm{h}, 65 \mathrm{~km} / \mathrm{h}$ and $80 \mathrm{~km} / \mathrm{h}$. The driving speeds of vehicles are set with comprehensive considerations to different requirements on urban road design and internal and external speed limits in cities. The speed limit of roads in a city is set $50 \mathrm{~km} / \mathrm{h}$ and that of roads out of a city is $65 \mathrm{~km} / \mathrm{h}$. According to urban road design norms in China, the traffic capacities of roads with designed speeds of $50 \mathrm{~km} / \mathrm{h}$ and $65 \mathrm{~km} / \mathrm{h}$ is $1660 \mathrm{pcu} / \mathrm{h}$ and $1850 \mathrm{pcu} / \mathrm{h}$, respectively.

Length of road $(\mathrm{km})$ is calculated based on the GIP software. According to the vehicle speed and length of roads, free driving time on each road can be calculated ( $\mathrm{min}$ ). Traffic flow in a specific period of a road is gained from GPS data and the LAC sequence analysis method.

Traffic control applies the three-phase traffic light control at a period of $140 \mathrm{~s}$ : $60 \mathrm{~s}$ for straight driving, $20 \mathrm{~s}$ for turning left, $2 \mathrm{~s}$ of yellow light and $58 \mathrm{~s}$ of red light.

\subsection{Selection of the optimal path under normal traffic lights}

Combined with practical situations of road sections from City A to City D under normal traffic loads, data of the different road sections and road junctions are acquired from TransCAD simulation software of traffic distribution. Results are shown in Figs. 3 a, 3 b and 4 .

Periodic time of traffic lights is $140 \mathrm{~s}$ and the proportion of green lights is 0.429 . The above data are applied into the road impedance function model in this study. The driving times in different sections are also calculated (Table II).

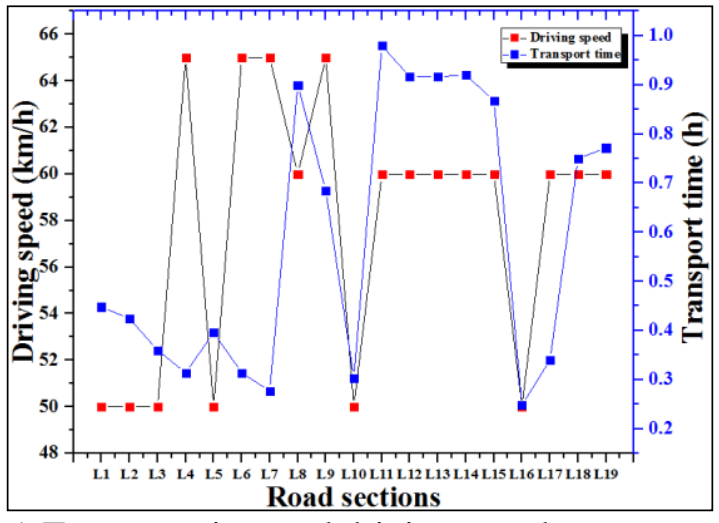

a) Transport time and driving speed

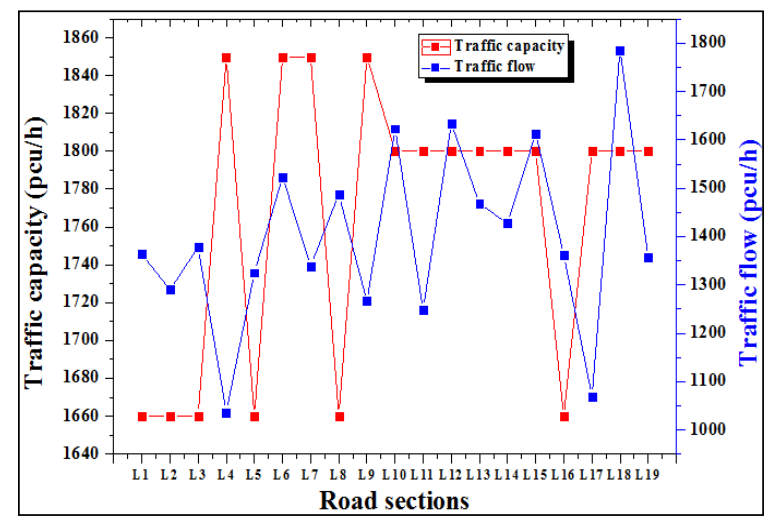

b) Traffic capacity and flow

Figure 3: Data of the different road sections under normal traffic conditions. 


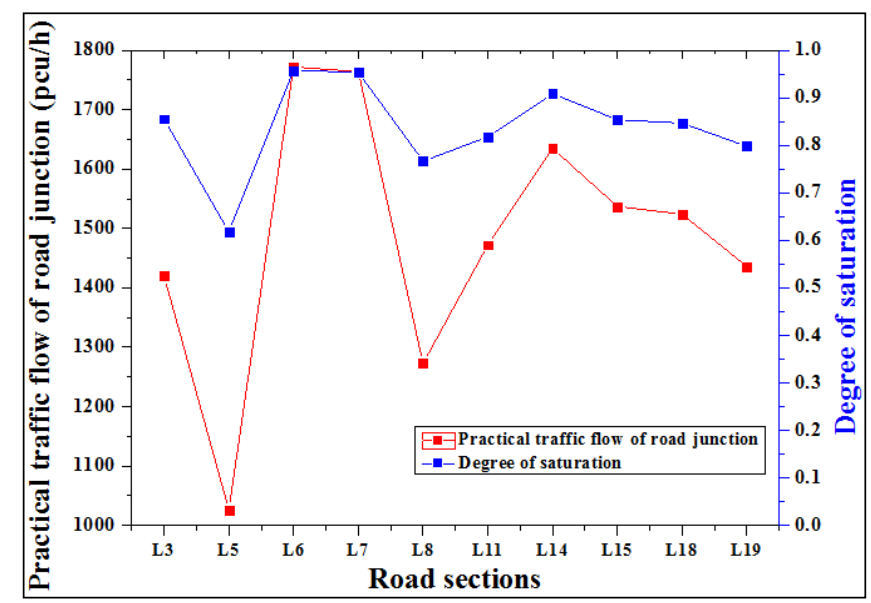

Figure 4: Data of the road junction in different sections under normal traffic conditions.

Table II: Driving time of different sections under normal traffic conditions.

\begin{tabular}{|c|c|c|c|c|c|c|c|}
\hline $\begin{array}{c}\text { Road } \\
\text { section }\end{array}$ & $\begin{array}{c}\text { Driving } \\
\text { time (min) }\end{array}$ & $\begin{array}{c}\text { Road } \\
\text { section }\end{array}$ & $\begin{array}{c}\text { Driving } \\
\text { time (min) }\end{array}$ & $\begin{array}{c}\text { Road } \\
\text { section }\end{array}$ & $\begin{array}{c}\text { Driving } \\
\text { time (min) }\end{array}$ & $\begin{array}{c}\text { Road } \\
\text { section }\end{array}$ & $\begin{array}{c}\text { Driving } \\
\text { time (min) }\end{array}$ \\
\hline L1 & 26.6 & L6 & 18.76 & L11 & 38.83 & L16 & 12.79 \\
\hline L2 & 17.05 & L7 & 14.27 & L12 & 45.88 & L17 & 14.7 \\
\hline L3 & 17.01 & L8 & 27.77 & L13 & 34.84 & L18 & 36.66 \\
\hline L4 & 12.44 & L9 & 25.36 & L14 & 43.23 & L19 & 25.96 \\
\hline L5 & 15.21 & L10 & 14.26 & L15 & 48.13 & - & - \\
\hline
\end{tabular}

Based on the above data, adjacent matrix of the road junction can be gained. Then, according to adjacent matrix based on driving time in different sections, Matlab software is used to obtain the following path with the shortest time: L2-L5-L6-L9-L14. The optimal transport time is $119.61 \mathrm{~min}$. The optimal path is shown in Fig. 5.

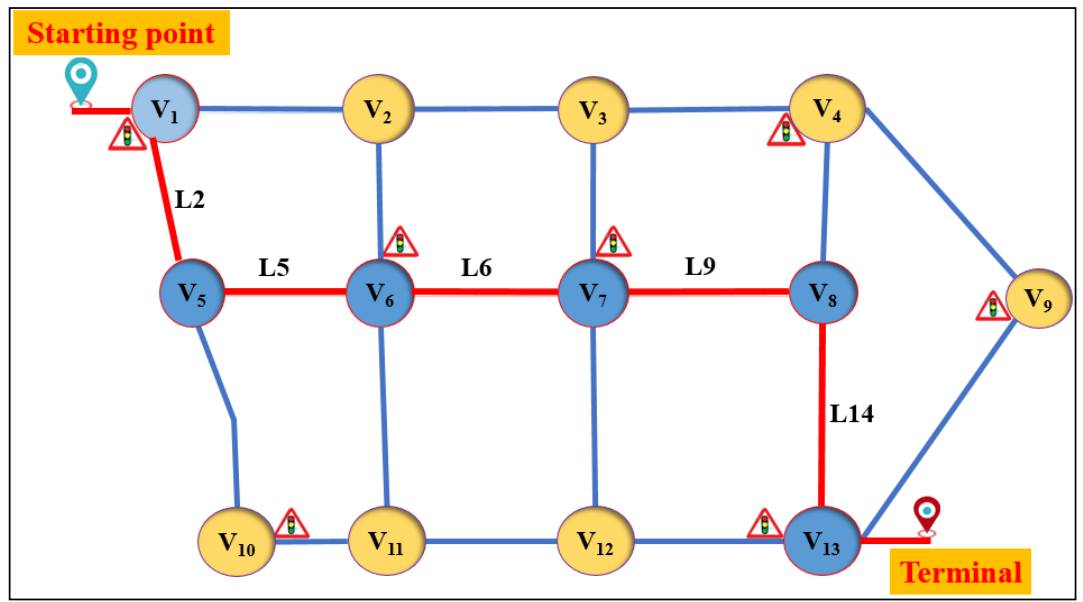

Figure 5: Optimal path under normal traffic lights.

The total length of the optimal path is about $124.4 \mathrm{~km}$. According to the shortest transport time, the average speed is about $62.4 \mathrm{~km} / \mathrm{h}$, which has practical significance. This verifies feasibility of road impedance model.

\subsection{Selection of the optimal path under rainfall condition}

The optimal path under normal traffic flows is selected based on the above calculation. With consideration to the influences of meteorological factors on the transportation of practical 
emergency relief supplies, an experiment of optimal path under rain conditions is carried out. Rainfall may cause poor visibility and slippery wet road conditions. Under this circumstance, fast turning or braking can easily cause accidents. Hence, rainfall may affect driving speed, traffic capacity and traffic flows of roads to some extent. To ensure the safe arrival of emergency relief supplies in time, the optimal path is selected with the assistance of the road impedance model and the Dijkstra algorithm (Fig. 6).

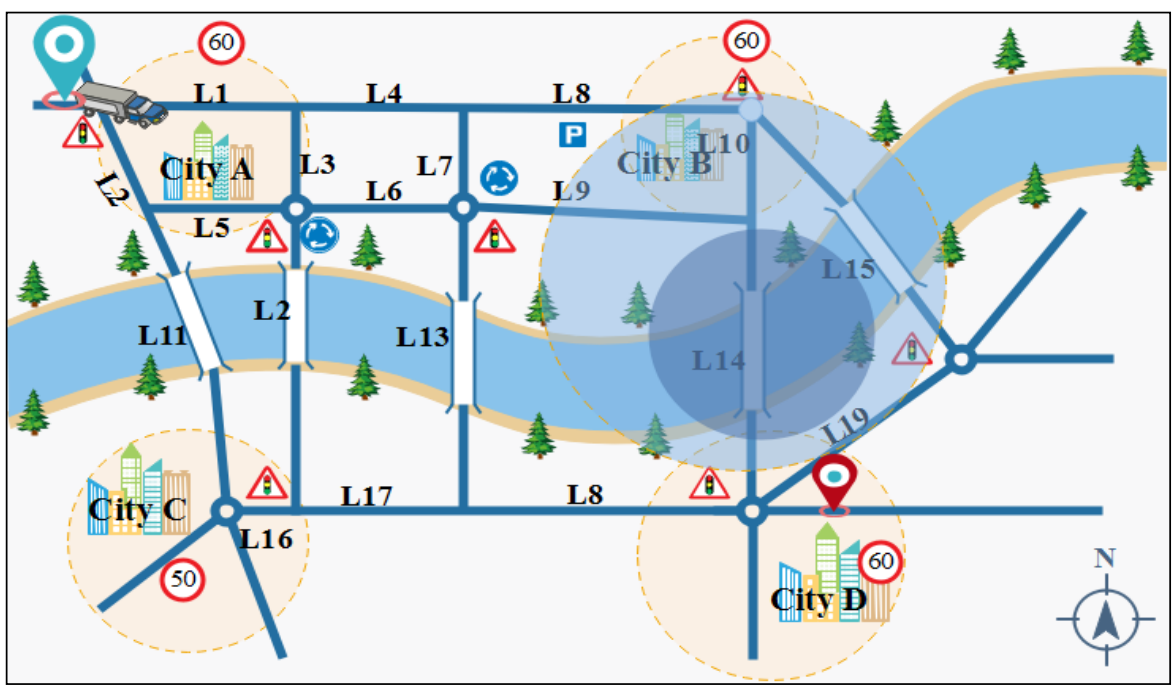

Figure 6: Path network topology under rain conditions.

As shown in Fig. 6, there's small rain in the light shadow region and heavy rain in the deep shadow region. Combined with the GPS of vehicles and rainfall data in meteorological stations, significance analysis and correlation analysis are applied. A numerical simulation of road sections within the sphere of rainfall is carried out.

Through a comparison of traffic flows in different sections under rainfall condition, data in different road sections and road junctions of different road sections can be obtained. They are presented in Figs. $7 \mathrm{a}, 7 \mathrm{~b}$ and 8.

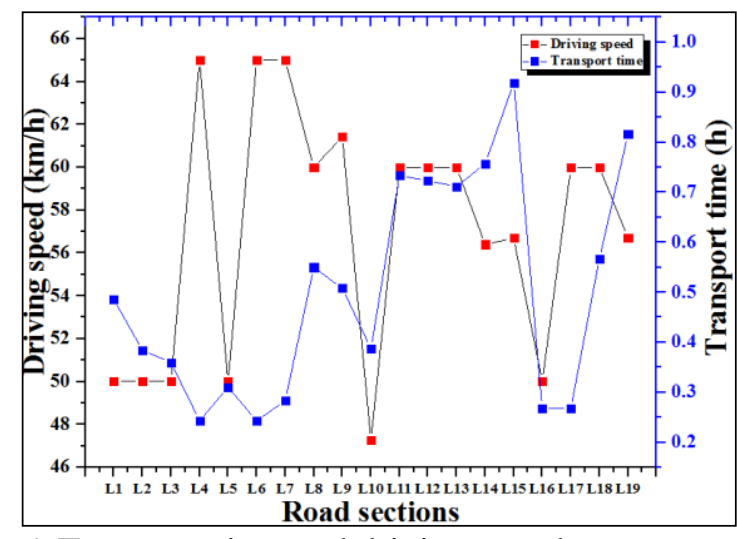

a) Transport time and driving speed

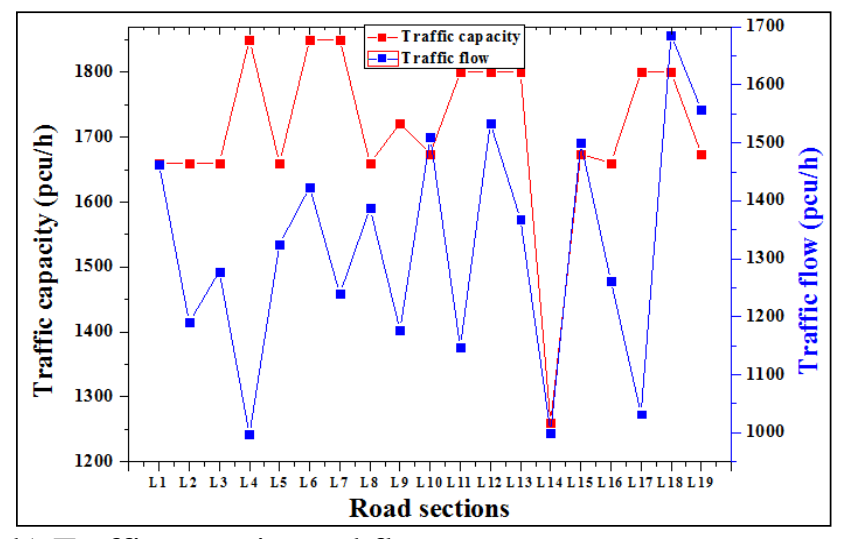

b) Traffic capacity and flow

Figure 7: Data of different road sections under rainfall condition.

The road impedance function is simulated based on data in Figs. 7 and 8, ultimately generating time cost $(T)$ on different sections. The results are listed in Table III. 


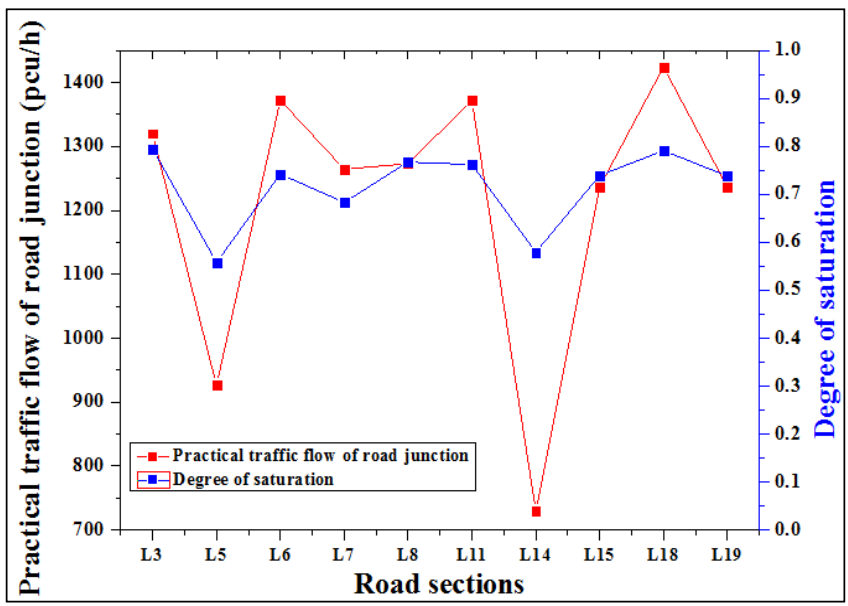

Figure 8: Data of road junctions in different sections under rainfall condition.

Table III: Time cost of different sections under rainfall conditions.

\begin{tabular}{|c|c|c|c|c|c|c|c|}
\hline $\begin{array}{c}\text { Road } \\
\text { section }\end{array}$ & $\begin{array}{c}\text { Driving } \\
\text { time (min) }\end{array}$ & $\begin{array}{c}\text { Road } \\
\text { section }\end{array}$ & $\begin{array}{c}\text { Driving } \\
\text { time (min) }\end{array}$ & $\begin{array}{c}\text { Road } \\
\text { section }\end{array}$ & $\begin{array}{c}\text { Driving } \\
\text { time (min) }\end{array}$ & $\begin{array}{c}\text { Road } \\
\text { section }\end{array}$ & $\begin{array}{c}\text { Driving } \\
\text { time (min) }\end{array}$ \\
\hline L1 & 26.73 & L6 & 18.86 & L11 & 38.85 & L16 & 12.81 \\
\hline L2 & 17.06 & L7 & 14.27 & L12 & 44.91 & L17 & 14.71 \\
\hline L3 & 17.13 & L8 & 28.62 & L13 & 35.62 & L18 & 36.72 \\
\hline L4 & 12.52 & L9 & 27.13 & L14 & 45.13 & L19 & 27.82 \\
\hline L5 & 15.43 & L10 & 15.24 & L15 & 49.42 & - & - \\
\hline
\end{tabular}

Based on above data, time costs $(T)$ of different sections are gained from analysis and operation, thereby yielding the adjacent matrix of road junctions. With the adjacent matrix of road junctions, the Dijkstra algorithm is programmed and solved by Matlab software, resulting in the optimal path under rain conditions: L2-L11-L16-L17-L18. The total length of this optimal path is $126.7 \mathrm{~km}$ and the relevant time $T$ is $120.15 \mathrm{~min}$. The average speed is $63.27 \mathrm{~km} / \mathrm{h}$. The optimal path is shown in Fig. 9, and time cost under different rainfall conditions is shown in Fig. 10. At this moment, $T$ of this optimal path is $120.15 \mathrm{~min}$, which is slightly higher than the time cost (120.03 $\mathrm{min})$ of the path when there is no rainfall. This time is $0.5 \%$ higher than the time cost (119.61 min) of the original optimal path.

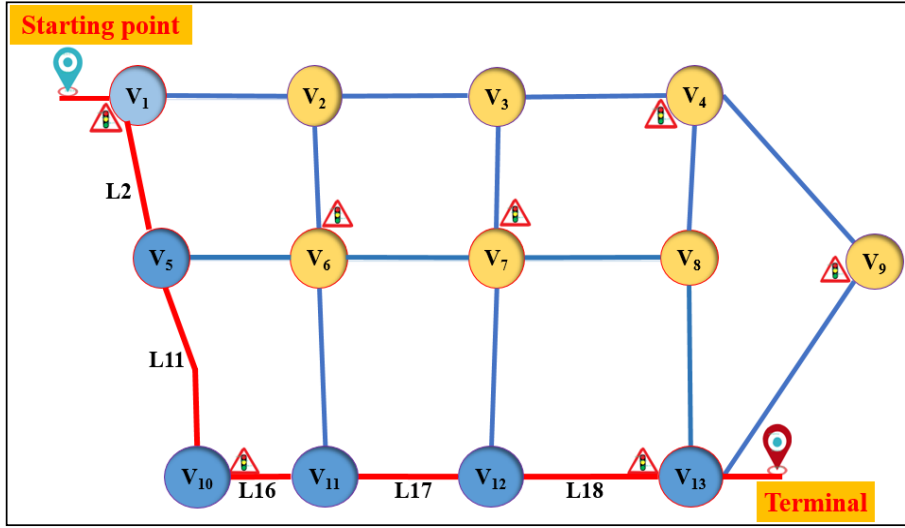

Figure 9: Optimal path under rainfall conditions.

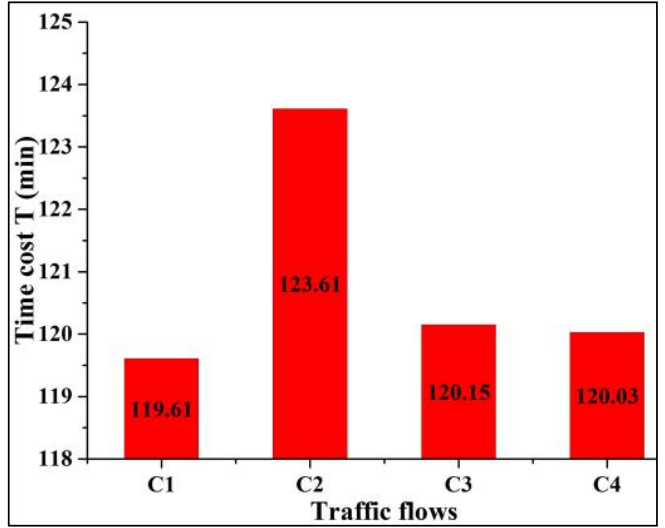

Figure 10: Time cost under different rainfall conditions.

The time $T$ of the original optimal path during rainfall is $123.61 \mathrm{~min}$, which is $3.3 \%$ higher. As a result, the optimal path is changed slightly as a response to rainfall in the region. 
$\mathrm{C} 1$ and $\mathrm{C} 2$ reflect the rainfall condition and non-rainfall condition of the original optimal path. $\mathrm{C} 3$ and $\mathrm{C} 4$ are the traffic conditions of the optimal path under rainfall condition when there is rainfall or no rainfall.

Traffic flows in rainfall sections decrease under rainfall condition, but the driving speed of vehicles decreases significantly. As a result, the driving time of vehicles on rainfall sections is generally increased. The traffic capacity and driving speed under a condition in which there is a small amount rainfall are decreased by $4 \%-10 \%$ and $5 \%-6.5 \%$, respectively. Moreover, the traffic capacity and driving speed under heavy rainfall are decreased by $25 \%-35 \%$ and $5 \%$ $6 \%$, respectively. Therefore, the constructed model is highly applicable in selecting the optimal transport path under rainfall condition.

\subsection{Selection of the optimal path under traffic control conditions}

There are many uncertainty factors in traffic roads. Road construction, traffic accidents and force majeure are the main causes of traffic control. Supposing L2 and L8 adopt a traffic control due to force majeure, this would mean that all vehicles are prohibited from passing.

Under traffic control conditions, the adjacent open sections must share traffic capacity and traffic flows. In this case, traffic flows in different sections are simulated, thus yielding the number of sections (Figs. $11 \mathrm{a}, 11 \mathrm{~b}$ and 12).

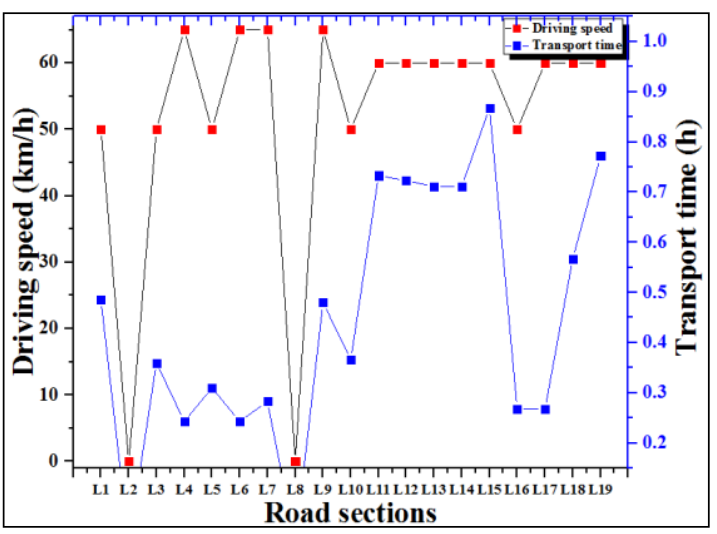

a) Transport time and driving speed

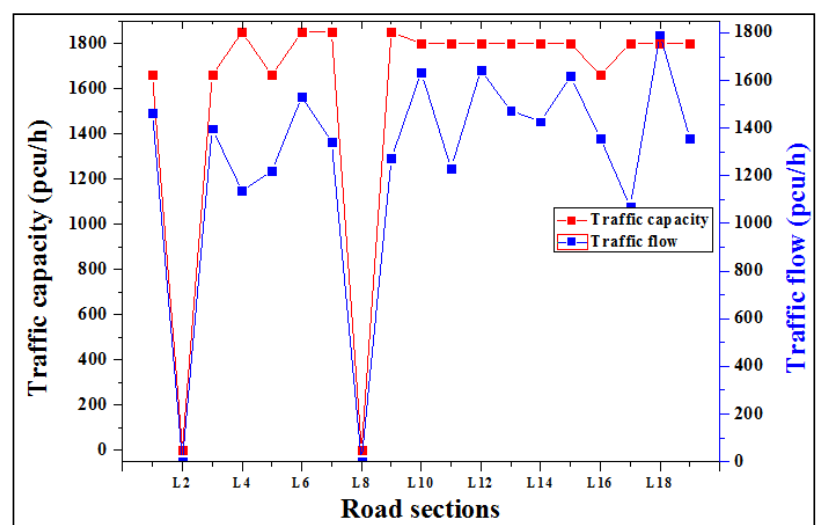

b) Traffic capacity and flow

Figure 11: Data of different road sections under traffic control conditions.

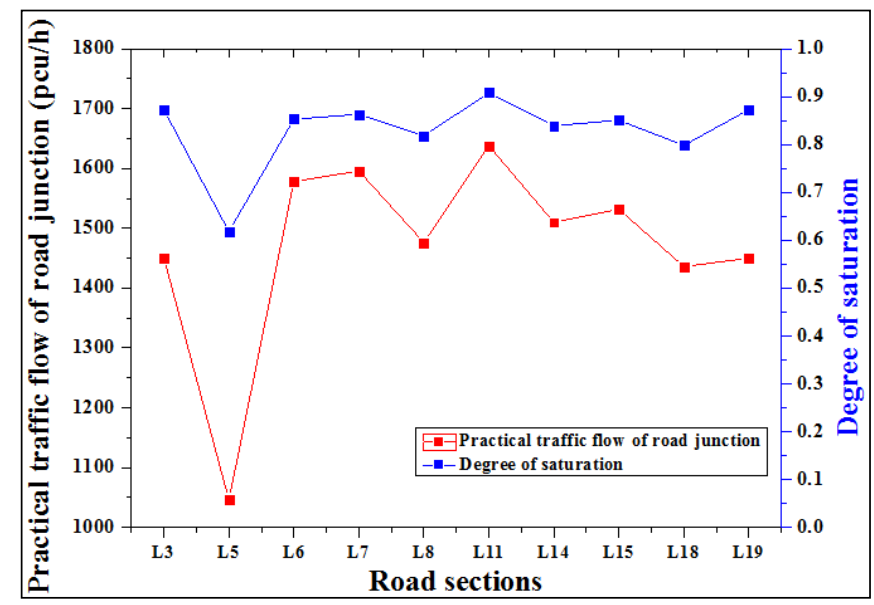

Figure 12: Data of road junctions in different sections under traffic control conditions.

The data in Figs. 11 and 12 are processed through the road impedance function model, which determines the time cost in L2 and L8 under traffic control (Table IV). 
Table IV: Time cost of different sections under traffic control conditions.

\begin{tabular}{|c|c|c|c|c|c|c|c|}
\hline $\begin{array}{c}\text { Road } \\
\text { section }\end{array}$ & $\begin{array}{c}\text { Driving } \\
\text { time (min) }\end{array}$ & $\begin{array}{c}\text { Road } \\
\text { section }\end{array}$ & $\begin{array}{c}\text { Driving } \\
\text { time (min) }\end{array}$ & $\begin{array}{c}\text { Road } \\
\text { section }\end{array}$ & $\begin{array}{c}\text { Driving } \\
\text { time (min) }\end{array}$ & $\begin{array}{c}\text { Road } \\
\text { section }\end{array}$ & $\begin{array}{c}\text { Driving } \\
\text { time (min) }\end{array}$ \\
\hline L1 & 26.3 & L6 & 18.43 & L11 & 44.78 & L16 & 12.83 \\
\hline L2 & 20.21 & L7 & 18.56 & L12 & 35.27 & L17 & 15.83 \\
\hline L3 & 12.66 & L8 & 25.42 & L13 & 42.17 & L18 & 37.21 \\
\hline L4 & 17.32 & L9 & 17.27 & L14 & 49.24 & L19 & 26.23 \\
\hline L5 & 26.3 & L10 & 39.32 & L15 & 44.78 & - & - \\
\hline
\end{tabular}

Based on time costs $(T)$ in Table IV, an adjacent matrix of road junction can be established. By the combining adjacent matrices of the time cost of different sections under traffic control, the Dijkstra algorithm is programmed and solved by Matlab software, ultimately yielding the optimal path: L1-L4-L7-L9-L14 (Fig. 13).

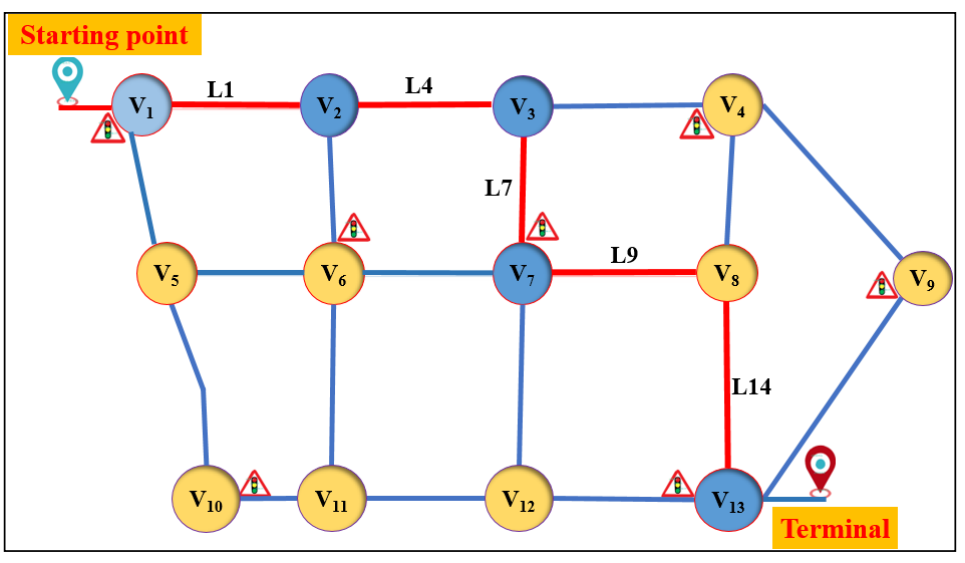

Figure 13: The optimal path under traffic control.

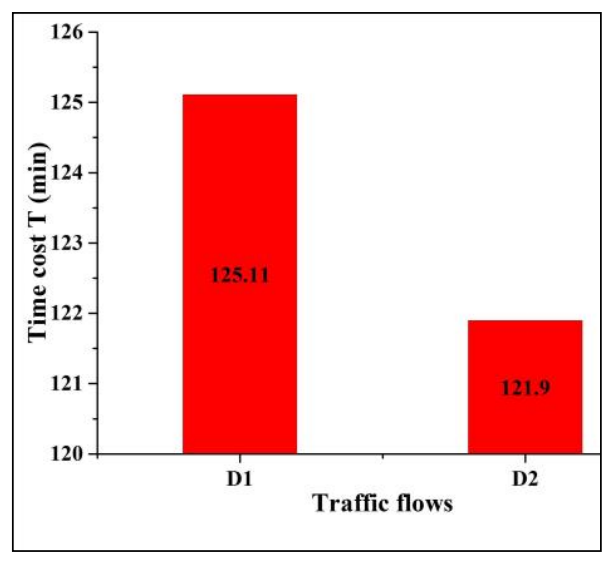

Figure 14: Time cost of the optimal path under different traffic controls.

The length of this optimal path is $132.4 \mathrm{~km}$ and the corresponding time cost $(T)$ is 125.11 $\min$. The average speed is $63.5 \mathrm{~km} / \mathrm{h}$. Under no traffic control, $T$ of this path is $121.9 \mathrm{~min}$.

As shown in Fig. 14, D1 and D2 are the optimal paths under the conditions of traffic control or no traffic control, respectively. $T$ under traffic control is $1 \%$ higher than that under no traffic control. On the one hand, L2 in the original optimal path is closed due to the traffic control, so the optimal path is changed. On the other hand, traffic flows on other road sections are changed because of traffic control, which increases $T$ accordingly. These prove that the road impedance model and the Dijkstra algorithm are applicable predicting the optimal path under traffic control.

\section{CONCLUSION}

In this study, a road impedance function model was constructed for the quantitative analysis of traffic impedance and the selection of the optimal path with minimum according to the practical road traffic flows. The road impedance model considered the impedance of different sections and traffic flows at road junctions with traffic lights. The optimal transport paths for emergency relief supplies under normal condition, rainfall condition and traffic control were respectively calculated. Conclusions are drawn as follows.

(1) According to the case study, the weight of path is selected scientifically and the Dijkstra algorithm achieves a high accuracy.

(2) Combined with regional rainfall, the optimal path is changed, but the total $T$ of the optimal path changes slightly. The optimal path under rainfall condition corresponds to a low 
$T$ for the transportation of emergency relief supplies. However, $T$ of the optimal path under rainfall condition is $0.5 \%$ higher compared with that when there is no rainfall. In comparison, $T$ of the optimal path under normal condition is $3.3 \%$ higher than that when there is rainfall.

(3) The optimal path under traffic control is selected wherein $T$ is increased by $1 \%$. Hence, traffic control may affect other traffic flows on other sections and increase $T$ accordingly.

Based on the road impedance model and traffic distribution simulation data, the road impedance model is solved by using the Dijkstra algorithm based on the weight of path. All three cases indicate that the weights of paths from the road impedance model are selected scientifically. Thus, the constructed road impedance function model proves its universality. However, there are more factors affecting the optimal path from these three conditions in this study. Therefore, in the next step, more simulations under various conditions should be considered and carried out.

\section{ACKNOWLEDGEMENT}

This work was supported by the sub-topic of National Key Research and Development Project of China (Grant No. 2017YFC0805207), Graduate Education Innovation Program of Shandong Province (Grant No. SDYC15055), and Undergraduate Teaching and Reform Project of Shandong Province (Grant No. M2018X216).

\section{REFERENCES}

[1] Zhang, J. J.; Cliff, D.; Xu, K.; You, G. (2018). Focusing on the patterns and characteristics of extraordinarily severe gas explosion accidents in Chinese coal mines, Process Safety and Environmental Protection, Vol. 117, 390-398, doi:10.1016/j.psep.2018.05.002

[2] Wu, Q. S.; Jiang, L. S.; Wu, Q. L.; Xue, Y. C.; Gong, B. (2018). A study on the law of overlying strata migration and separation space evolution under hard and thick strata in underground coal mining by similar simulation, Dyna, Vol. 93, No. 2, 175-181, doi:10.6036/8678

[3] Wang, H. W.; Xue, S.; Jiang, Y. D.; Deng, D. X.; Shi, S. Z.; Zhang, D. Q. (2018). Field investigation of a roof fall accident and large roadway deformation under geologically complex conditions in an underground coal mine, Rock Mechanics and Rock Engineering, Vol. 51, No. 6, 1863-1883, doi: 10.1007/s00603-018-1425-1

[4] Chen, L. W.; Feng, X. Q.; Xu, D. Q.; Zeng, W.; Zheng, Z. Y. (2018). Prediction of water inrush areas under an unconsolidated, confined aquifer: the application of multi-information superposition based on GIS and AHP in the Qidong coal mine, China, Mine Water and the Environment, Vol. 37, No. 4, 786-795, doi:10.1007/s10230-018-0541-1

[5] Xie, X.-F.; Wang, Z. J. (2019). Combined traffic control and route choice optimization for traffic networks with disruptive changes, Transportmetrica B: Transport Dynamics, Vol. 7, No. 1, 814833, doi: $10.1080 / 21680566.2018 .1517059$

[6] Groot, N.; De Schutter, B.; Hellendoorn, H. (2014). Toward system-optimal routing in traffic networks: A reverse Stackelberg game approach, IEEE Transactions on Intelligent Transportation Systems, Vol. 16, No. 1, 29-40, doi:10.1109/TITS.2014.2322312

[7] Luisa De Maio, M.; Vitetta, A. (2015). Route choice on road transport system: a fuzzy approach, Journal of Intelligent \& Fuzzy Systems, Vol. 28, No. 5, 2015-2027, doi:10.3233/IFS-141375

[8] Kim, J.; Lee, S.; Lee, S. (2017). An evacuation route choice model based on multi-agent simulation in order to prepare Tsunami disasters, Transportmetrica B: Transport Dynamics, Vol. 5, No. 4, 385-401, doi:10.1080/21680566.2016.1147002

[9] Duell, M.; Saxena, N.; Chand, S.; Amini, N.; Grzybowska, H.; Waller, S. T. (2016). Deployment and calibration considerations for large-scale regional dynamic traffic assignment: case study for Sydney, Australia, Transportation Research Record - Jounal of the Transportation Research Board, Vol. 2567, No. 1, 78-86, doi:10.3141/2567-09

[10] Meneguzzer, C. (2012). Dynamic process models of combined traffic assignment and control with different signal updating strategies, Journal of Advanced Transportation, Vol. 46, No. 4, 351-365, doi:10.1002/atr.1199 
[11] Hanczar, P.; Kaleta, J. (2016). Inventory routing problem in rolling horizon planning environment, Transformations in Business \& Economics, Vol. 15, No. 2A (38A), 373-388

[12] Meng, M.; Shao, C. F.; Zeng, J. J.; Dong, C. J. (2014). A simulation-based dynamic traffic assignment model with combined modes, Promet - Traffic \& Transportation, Vol. 26, No. 1, 6573, doi:10.7307/ptt.v26i1.1252

[13] Florian, M.; Mahut, M.; Tremblay, N. (2008). Application of a simulation-based dynamic traffic assignment model, European Journal of Operational Research, Vol. 189, No. 3, 1381-1392, doi:10.1016/j.ejor.2006.07.054

[14] Marcianò, F. A.; Musolino, G.; Vitetta, A. (2011). Within-day traffic assignment and signal setting in road evacuation: a procedure with explicit path enumeration, WIT Transactions on the Built Environment, Vol. 117, 403-414, doi:10.2495/SAFE110351

[15] Marcianò, F. A.; Musolino, G.; Vitetta, A. (2015). Signal setting optimization on urban road transport networks: the case of emergency evacuation, Safety Science, Vol. 72, 209-220, doi:10.1016/j.ssci.2014.08.005

[16] Cantarella, G. E.; Vitetta, A. (2006). The multi-criteria road network design problem in an urban area, Transportation, Vol. 33, No. 6, 567-588, doi:10.1007/s11116-006-7908-Z

[17] Yu, H.; Ma, R.; Zhang, H. M. (2018). Optimal traffic signal control under dynamic user equilibrium and link constraints in a general network, Transportation Research Part B: Methodological, Vol. 110, 302-325, doi:10.1016/j.trb.2018.02.009

[18] Lee, S.; Wong, S. C.; Varaiya, P. (2017). Group-based hierarchical adaptive traffic-signal control part I: Formulation, Transportation Research Part B: Methodological, Vol. 105, 1-18, doi:10.1016/j.trb.2017.08.008

[19] Sirmatel, I. I.; Geroliminis, N. (2017). Economic model predictive control of large-scale urban road networks via perimeter control and regional route guidance, IEEE Transactions on Intelligent Transportation Systems, Vol. 19, No. 4, 1112-1121, doi:10.1109/TITS.2017.2716541

[20] Jamshidnejad, A.; Papamichail, I.; Papageorgiou, M.; De Schutter, B. (2017). Sustainable modelpredictive control in urban traffic networks: Efficient solution based on general smoothening methods, IEEE Transactions on Control Systems Technology, Vol. 26, No. 3, 813-827, doi: $10.1109 /$ TCST.2017.2699160

[21] Lin, S.; De Schutter, B.; Xi, Y. G.; Hellendoorn, H. (2012). Efficient network-wide model-based predictive control for urban traffic networks, Transportation Research Part C: Emerging Technologies, Vol. 24, 122-140, doi:10.1016/j.trc.2012.02.003

[22] Wang, J. S.; Cao, C. D.; Zeng, S. Z.; Balezentis, T. (2019). Weighted induced aggregation Euclidean distance operators for the decision making of robot selection, Transformations in Business \& Economics, Vol. 18, No. 1 (46), 81-94 